DOI 10.5216/ia.v46i2.67954

\title{
ESCOLARIZAÇÃO ÉTNICA ITALIANA E CULTURA ESCOLAR EM SÃO PAULO: AS INICIATIVAS DE GAETANO NESI E GEMMA MANETTI PELA INFÂNCIA ESCOLAR ITALIANA ENTRE O FINAL DO SÉCULO XIX E O INÍCIO DO SÉCULOXX
}

\author{
AlberTo BARAusSE \\ Università degli Studi del Molise (UNIMOL), Campobasso, Itália
}

\begin{abstract}
Resumo: O texto recorre a fontes inéditas para apresentar a proposta de uma investigação da rede das escolas elementares italianas promovida no estado de São Paulo e da circulação dos saberes escolares pela infância italiana. O objetivo não é somente iniciar a reconstrução de um mapa das escolas italianas no contexto paulista e paulistano, mas, também, de esclarecer a sua natureza (associativa, privada, subsidiada, religiosa, etc.), as características (articulação e composição das turmas mistas por idade ou por sexo, número de inscritos e efetivos, taxas de inscrição e formas de subsistência), a organização e os conteúdos educativos e pedagógicos (escola diurna e noturna, articulação em graus, ensino mnemônico ou ensino intuitivo, conteúdos curriculares incluindo história e geografia ou catequese) e as características, formação e condição dos professores. Nessa perspectiva, o texto pretende aprofundar o papel exercido pelo casal Gaetano Nesi e Gemma Manetti Nesi, promotores da instituição escolar Ai Nostri Monti e de iniciativa editorial para educar os filhos dos italianos e agilizar a aprendizagem da escrita e da leitura.
\end{abstract}

Palavras-chave: Escolarização Étnica Italiana. E/imigração Italiana em São Paulo. Cultura Escolar. Livros Escolares.

\section{INTRODUÇÃO}

O objetivo do presente artigo é, além de iniciar a reconstrução de um mapa das escolas italianas no contexto paulista e paulistano, esclarecer a sua natureza (associativa, privada, subsidiada, religiosa etc.), as características (articulação e composição das turmas mistas por idade ou por sexo, número de inscritos e efetivos, taxas de inscrição e formas de subsistência), a organização e os conteúdos educativos e pedagógicos e as caraterísticas, formação e condição dos professores. Nessa perspectiva, o texto pretende aprofundar o papel exercido pelo casal Gaetano Nesi e Gemma Manetti Nesi, promotores da instituição escolar Ai Nostri Monti.

Os processos de escolarização étnica constituem um campo recente de investigação, a partir de uma abordagem focada sobre a valorização da dimensão local (MAGALHÃES, 2018; BARAUSSE; GHIZZONI; MEDA, 2018) e transnacional da pesquisa, em torno dos quais atuam pesquisadores italianos e brasileiros (ASCENZI; BARAUSSE; LUCHESE; SANI, 2019). Experiências como as que pretendemos aprofundar neste artigo inserem-se em uma perspectiva de pesquisa muito mais ampla, que visa evidenciar o 
papel desempenhado pelos imigrantes italianos no seu estabelecimento na sociedade brasileira, iniciativas e práticas que visam impactar em uma dupla direção.

Por um lado, iniciativas como as conduzidas pelos cônjuges Nesi destinam-se a influenciar o crescimento da consciência do papel dos processos de educação e de alfabetização das massas imigrantes, conforme apontado por Luchese (2015) e Barausse (2017) para outros contextos no Brasil, como o estado do Rio Grande do Sul. Mas, por outro lado, a investigação oferece, enquanto análise e estudo dos processos educativos e das culturas escolares promovidos em contextos de imigração, uma perspectiva para compreender, antes de tudo, o papel e a função das instituições escolares como espaço de construção de identidade e de exercício de práticas de memória. Nesse sentido, é possível amparar-se no contexto histórico-educativo pelas contribuições produzidas pela mudança paradigmática iniciada com as reflexões de Julia (2001) e Frago (1995) sobre a cultura escolar, mas também com as de Pollak $(1989,1992)$ e as referências investigativas para a análise da formação da identidade étnica por meio do uso de categorias heurísticas de invenção e construção identitária que estudiosos como Conzen et al. (1992) e Hobsbawn (2002) desenvolveram nas últimas décadas.

\section{A EMIGRAÇÃO DE MASSA E AS ORIGENS DAS ESCOLAS ITALIANAS EM SÃO PAULO}

Sabemos que o estado de São Paulo foi o local onde ocorreu o fluxo imigratório italiano mais significativo para o Brasil (HALL, 2004). Os italianos que entraram entre 1888 e 1919 representaram 44,7\% da população imigrante, mas se restringirmos o foco ao período entre 1887 e 1902, a porcentagem de italianos que compuseram a população imigrante aumentará para 63,5\% (TRENTO, 1989, p. 107-124). Além disso, é necessário lembrar a distinção entre a imigração urbana e a imigração na área interna, a qual esteve ligada, pelo menos em parte, à colonização de áreas rurais (TRENTO, 2009; TRUZZI, 2016).

Desde o final dos anos 80 do século XIX, portanto, na onda do movimento imigratório, começaram a surgir iniciativas de escolarização para os filhos de emigrantes e em torno das quais a historiografia italiana e brasileira começaram a lançar luzes (ASCENZI; BARAUSSE; LUCHESE; SANI, 2019). No entanto, até o presente momento, ainda é difícil mapear quaisquer escolas que surgiram por iniciativa de muitos professores particulares nas áreas metropolitana e rural. Um primeiro mapeamento pode ser fornecido pelas fontes consulares e pelos anuários escolares (PANIZZOLO, 2020).

Em 1890, os imigrantes italianos não haviam fundado "uma verdadeira escola italiana correspondente às necessidades das numerosas famílias de ricos e prósperos compatriotas" (ROZWADOWSKI, 1890a, p. 1, tradução nossa). Não faltaram tentativas para alcançar a criação da escola, mas:

a desunião entre os vários elementos da colônia, devido ao excesso
de paroquialismo na região, desaparecido na Itália, e ressuscitado
no exterior, as contínuas pequenas inimizades e invejas entre eles, a
falta de um grupo de notáveis que por consenso, por honra, por
inteligência exercessem uma real influência sobre as massas e que
possa levá-las à execução de obras, cuja necessidade é reconhecida 
BARAUSSE, A.

por todos, sempre fez abortar os esforços dos poucos bemintencionados (ROZWADOWSKI, 1890a, p. 1, tradução nossa).

Os documentos analisados até o momento mostram a existência, em 1890, de 5 escolas particulares, mas também a tentativa de promover iniciativas para apoiar o desenvolvimento de instituições mais significativas ou importantes por meio de diferentes meios. O cônsul, no entanto, falou de um "despertar patriótico" e do possível estabelecimento de uma "grande sociedade entre os italianos", fatos que levaram o cônsul a um ter certo otimismo em relação às escolas (ROZWADOWSKI, 1890a, p. 2). O primeiro dos pontos do programa em construção envolveu o estabelecimento de uma escola.

As escolas criadas até então refletiam o comprometimento de indivíduos particulares, de professores dignos de elogios, porque transmitiam "uma instrução em italiano aos filhos dos italianos e os familiarizavam com as tradições do país" (ROZWADOWSKI, 1890a, p. 2, tradução nossa). Para o cônsul, no entanto, seguindo as circunstâncias locais, os professores não permitiram e impediram de seguir "um programa didático sério" (ROZWADOWSKI, 1890a, p. 2, tradução nossa). As escolas estavam mal estruturadas, não era possível falar em calendários precisos no que diz respeito às matrículas regulares, abertura ou encerramento de cursos. Ainda no que se refere à organização didática e pedagógica, o quadro era bastante precário, marcado pela ausência de escolas divididas em classes, com uma única sala na qual crianças de 4 a 14 anos se reuniam simultaneamente, sendo pouco efetiva, apesar de exigida pelas normas nacionais.

No entanto, os relatórios consulares atestam o rápido crescimento do número de escolas particulares em um período de quinze anos. Também nesse caso, além dos anuários, os relatórios dos cônsules revelam um fenômeno em clara expansão. Já no final do século, o cônsul Enrico Chicco registrou a presença de cerca de 50 escolas e 200 professores:

\begin{abstract}
As escolas italianas surgem na cidade de São Paulo e em todo o estado, como negócios e espaços de alimentos, sem nenhuma regra e sem nenhum controle. É suficiente um epitáfio na porta, uma cadeira, uma mesinha e alguns bancos para proclamar, através de um artigo da gazeta, [é] instituída uma escola italiana em São Paulo (CHICCO, 1897, p. 1, tradução nossa).
\end{abstract}

A lista de escolas italianas predispostas pelo cônsul Gioia anexa ao relatório de 15 de abril de 1900 registrava 70 escolas, com um total de 3408 alunos inscritos, dos quais 2811 frequentavam (GIOIA, 1900). Dois anos depois, o novo cônsul Monaco observou a presença de 45 escolas na cidade de São Paulo e 74 escolas pertencentes à Associação. O número de alunos era respectivamente de 2935 e 3400 para um total de 6335 alunos matriculados (MONACO, 1902). O cônsul Pio de Savoia indicou, em janeiro de 1906, referente ao ano de 1905, que o número de escolas existentes era de 83 , das quais 47 aceitaram ser supervisionadas pelo consulado de São Paulo, 13 pelo viceconsulado de Campinas, 9 pelo de São Carlos do Pinhal, 8 pelo de Ribeirão Preto, 5 pelos agentes consulares e 1 pelo vice-consulado de Santos. A população escolar atingiu, portanto, 5379 alunos, com uma média de 65 alunos por escola. Esse era o número 
médio, porque, na realidade, havia 12 escolas com mais de 100 alunos e 16 escolas que possuíam um número acima da média de alunos. É interessante ressaltar, no entanto, a observação do cônsul-geral de que o número de escolas era muito maior, mas que o relatório se referia apenas às escolas que concordaram em submeter-se ao controle e à supervisão das autoridades consulares (PIO DI SAVOIA, 1906a, p. 2).

Todas as escolas mencionadas anteriormente referiam-se a centros populacionais importantes o suficiente para fazer o cônsul dizer que não havia escola que "pudesse ser chamada de escola rural no sentido estrito da palavra" ${ }^{1}$ (PIO DI SAVOIA, 1906a, p. 3, tradução nossa).

O significativo crescimento quantitativo das escolas na cidade e no estado rapidamente evidenciou a insuficiência de baixos subsídios ministeriais. De uma nota do Embaixador Riva, datada de 24 de março de 1890, sabemos que o total de recursos destinados às escolas de São Paulo era de 7.000 liras (RIVA, 1890). Entre os meios financeiros para apoiar o desenvolvimento das escolas, além dos subsídios concedidos pelo ministério italiano, as autoridades consulares também tentaram registrar as celebrações patrióticas instituídas localmente em escolas, como a promovida por ocasião do aniversário da rainha quando foi organizada uma loteria que permitia a arrecadação de uma quantia considerável de $\mathrm{R} \$ \mathbf{6 6 6 . 0 0 0}$ para ser usada no desenvolvimento de uma escola (ROZWADOWSKI, 1890b). Quinze anos depois, o cônsul Pio de Savoia propôs um fundo total de 23 mil liras (PIO DI SAVOIA, 1906b, p. 2).

As dinâmicas que acompanharam o desenvolvimento das escolas eram complexas e envolviam diferentes âmbitos: do problema da insalubridade e precariedade dos espaços à organização didática e pedagógica, da má qualidade dos professores à indiferença dos pais dos alunos, da ausência ou escassez no suprimento do material escolar ao problema mais complexo do governo das escolas. Em mais de uma ocasião, as autoridades consulares recordaram em seus relatórios uma característica específica das escolas localizadas, sobretudo, no contexto metropolitano da cidade, aquela relacionada à forte mobilidade das escolas. De fato, o alto custo dos aluguéis produziu um fenômeno muito particular na cidade, o do movimento frequente dos espaços escolares, tanto que um cônsul definiu as escolas como "tendas móveis" (PIO DI SAVOIA, 1906a). Assim, as crianças em idade escolar eram frequentemente forçadas a perseguir o movimento físico dos espaços escolares. Por outro lado, os próprios professores se viram obrigados a administrar a forte mobilidade dos alunos, reflexo dos pais sujeitos à dinâmica do mercado de trabalho local.

A condição e a preparação dos professores, por outro lado, constituíam um problema sério: sua profissão era acompanhada de um forte espírito competitivo, apesar de: "poucos [serem] licenciados e poucos, mesmo aqueles que, licenciados ou não, merecem o nome de professores" (PIO DI SAVOIA, 1906a, p. 4, tradução nossa) e:

Quando cheguei aqui, no início de 1903, esses senhores mestres constituíam uma verdadeira ferida. Parecia que eles tinham o diabo em seus corpos, todos os dias havia brigas, gritos, dentro e fora do Consulado, controvérsias jornalísticas - e quais "- reivindicações ridículas, rebeliões". Para disciplinar as relações com os professores, o cônsul começou a reconstruir os caminhos biográficos dos 
BARAUSSE, A.

\begin{abstract}
mestres individuais, de modo a induzir muitos deles a abandonar o terreno da controvérsia e aceitar e reconhecer a autoridade consular. Ao mesmo tempo, ele estabeleceu a alocação de subsídios, tentando favorecer os melhores e eliminar "os elementos de qualidade inferior". A situação parecia ter melhorado, mas, como característica constante, "a competição que os mestres fazem entre si e que deve ser desencorajada e vencida, pelo menos em certa medida, como a que tem o objetivo de roubar os alunos mutuamente, aproveitando a preguiça, a avareza e a ignorância dos pais a quem, em geral, para gastar pouco, não importa que seus filhos frequentem uma escola e não outra (PIO DI SAVOIA, 1906a, p. 4, tradução nossa).
\end{abstract}

Desde o início, não foi fácil para as autoridades consulares formular uma avaliação das escolas étnicas italianas. Pio de Savoia foi bastante claro ao apontar que "não divido o desprezo que muitos, sem reflexão e sem conhecimento suficiente dos fatos, professam por elas" (PIO DI SAVOIA, 1906a, p. 4); algumas foram consideradas "realmente boas e muito discretas" (PIO DI SAVOIA, 1906a, p. 4). As escolas primárias que ele teve a oportunidade de visitar na Itália não possuíam uma condição melhor que aquelas:

\begin{abstract}
No geral, no entanto, não tenho dificuldade em me associar com aqueles que descobriram que essas escolas valem pouco; mas quando se pensa que são professores improvisados, crianças em idade escolar recrutadas nas famílias de trabalhadores pobres que estão aqui hoje e amanhã correndo atrás do trabalho, quando se pensa que professores e crianças em idade escolar receberam apoio apenas insignificantes e que milagres não podem ser esperados de ninguém, creio que essas escolas, assim como são, merecem todas as simpatias de cavalheiros e pessoas de bom senso e que todos devemos tentar fazer algo por eles e trazer cada um, uma gota de óleo nessas pobres lâmpadas suspensas no escuro, símbolo também dessa fé que todos temos nos destinos da pátria (PIO DI SAVOIA, 1906a, p. 4-5, tradução nossa).
\end{abstract}

O crescimento espontâneo e vertiginoso das escolas particulares levou os expoentes mais dinâmicos do contexto magistral da colônia a promoverem o estabelecimento de uma "Associação entre os professores italianos de São Paulo". O objetivo da associação não era apenas "juntar os professores italianos do estado de $\mathrm{S}$. Paulo" (STATUTO, 1902, p. 3, tradução nossa) ou "difundir a língua e a cultura pátria" (STATUTO, 1902, p. 3, tradução nossa), razão pela qual foi formada no Comitê de Dante Alighieri em Roma, mas, também, a de desempenhar uma função de gestão e coordenação das escolas italianas. "Tratava-se de dar um endereço mais estável a várias escolas, tentando agrupá-las e fundi-las em institutos mais bem equipados, com professores, materiais escolares, instalações; coletar presentes e ofertas em livros e dinheiro para formar um gabinete de leitura; organizar conferências, festas escolares e etc." (STATUTO, 1902, p. 3). Podiam fazer parte professoras e professores das escolas italianas de São Paulo que praticavam louvadamente a profissão e adotavam os programas de ensino da associação. Inicialmente, as autoridades consulares apoiaram-se 
na parceria para tentar promover uma direção mais eficaz das escolas. De fato, a direção e a administração da sociedade foram confiadas a uma delegação escolástica composta por quatro membros e ao cônsul real que ocupava o cargo de presidente. Dos quatro membros da comissão, pelo menos dois tinham que ser professores pertencentes à associação e nomeados sob proposta do cônsul.

Sucessivamente, no entanto, as autoridades consulares interviram para introduzir algumas mudanças, a fim de tornar a função de coordenação e controle mais eficaz e, sobretudo, direta, não apenas na distribuição de subsídios, mas, também, nas atividades. A esse respeito, Gherardo Pio di Savoia desenvolveu, para a gestão geral das escolas italianas em São Paulo, entre 1903 e 1905, um programa geral de reorganização a ser realizado durante seu mandato, além de prever intervenções em vários níveis: da gestão administrativa aos aspectos didáticos e financeiros. Em particular, o cônsul dissolveu a associação e aprovou um novo estatuto, juntamente com as regras para o funcionamento das escolas italianas no estado de São Paulo (1904), destinadas a garantir um maior controle na gestão e uma vigilância das escolas, confiadas à Delegação da Escola.

O projeto geral de reorganização das escolas também proporcionou um aprimoramento da intervenção financeira do estado italiano, através da preparação de um plano financeiro com base na possibilidade de subsidiar um número total de dez escolas que tentavam incentivar um processo de agregação e fusão entre as escolas. As quatro escolas internas eram em Campinas, Santos, São Carlos do Pinhal e Ribeirão Preto. Ao lado delas, deveriam ter sido escolhidas as seis escolas localizadas na cidade, que obteriam progressivamente um subsídio mais substancial. Em alguns casos, o caminho sugerido era incentivar a responsabilidade direta da administração das escolas pelas associações de caridade e de assistência mútua, como aconteceu em Santos com a instituição de caridade italiana e em Campinas com o Círculo Unido da Itália. Por fim, o sistema previa a possibilidade de subsidiar o restante das escolas localizadas nos centros menores e áreas rurais por meio de material escolar (PIO DI SAVOIA, 1906a, p. 11).

Durante seu mandato, o cônsul também introduziu novos critérios para a distribuição de subsídios, definindo uma tabela que incluía nas qualificações do mestre, as qualidades de ensino e os seus precedentes (seja de posse ou não de uma licença), méritos da história de sua escola, do ano em que foi fundada, da conduta do professor no Brasil e, especialmente durante o ano letivo, do número de alunos, do estado das instalações, da higiene, das premissas, das interrupções no ensino, do julgamento geral, derivado de visitas às escolas ao longo do ano, sobre o ensino (a educação e a instrução), os exames e etc. (PIO DI SAVOIA, 1906a, p. 20; PIO DI SAVOIA, 1906b, p. 7).

Finalmente, para garantir a distribuição dos materiais escolares, o cônsul desenvolveu um projeto muito interessante e pioneiro para reformar o suprimento de livros didáticos que pretendia mudar o centro da produção da Itália para o Brasil (PIO DI SAVOIA, 1906b, p. 19). O processo de reorganização, aplicado apenas parcialmente, pareceu dar alguns primeiros resultados. Segundo um relatório de 1906, tanto os professores quanto as sociedades de mútuo socorro, que administravam as escolas, havia dobrado seus esforços para "merecer a benevolência deste consulado e do Ministério Superior" (PIO DI SAVOIA, 1906b, p. 5). Os primeiros foram induzidos a 
BARAUSSE, A.

procurar um local mais conveniente, com mesas mais adequadas ou outros móveis escolares necessários e, os últimos, a equiparem-se de pessoal docente suficiente para o ensino. Ambos observaram uma disciplina "à qual antes não estavam acostumados, como a constante polêmica nos jornais provava, toda feita de fofocas, de personalidades, de insultos e de corrupções" (PIO DI SAVOIA, 1906b, p. 5, tradução nossa).

A alta taxa de conflito entre professores parecia ter retornado a níveis aceitáveis. Não que as tensões tivessem desaparecido completamente, mas pareciam, agora, limitadas e criadas principalmente por professores que não queriam aceitar o controle do consulado. Por fim, a opinião sobre as escolas étnicas italianas continuou positiva:

querendo ou não querendo, como são, com todas as suas falhas, nunca me cansarei de dizer - sinalizaram serviços à causa nacional na luta contra o analfabetismo e contra o indiferentismo da maioria por tudo relacionado ao decoro da pátria. É para essas escolas que, se queremos ou não, devemos se milhares e milhares de crianças italianas no estado de São Paulo souberem ler e escrever em italiano (PIO DI SAVOIA, 1906b, p. 1, tradução nossa).

\section{O CASAL MANETTI NESI E O COLÉGIO A/NOSTRI MONTI}

É nesse contexto complexo e dinâmico que também se classifica o nascimento, em 21 de janeiro de 1895, do Colégio-interno italiano e de uma escola primária mista anexa intitulada Ai nostri Monti. A escola foi promovida pelos cônjuges Gaetano Nesi e Giovanna Manetti Nesi, dois professores emigrantes italianos, dos quais, até agora, pouco se sabe. O que sabemos deriva da consulta de alguns relatórios enviados ao Ministério em resposta à solicitação de informações. Essas informações eram requisitadas pelo Ministério italiano, para que este soubesse, entre outras coisas, se a escola "alcança o objetivo de difundir, com as noções de língua italiana, o sentimento patriótico naquela numerosa colônia de nossos compatriotas" (TORRACA, 1897).

O instituto estava sediado na rua Principe di Napoli, n 13 , em uma sala bastante grande, localizada em "um local agradável e pitoresco", conforme indicado no folheto publicitário. O colégio foi considerado uma das melhores escolas italianas da região e foi amplamente divulgado nas páginas do jornalismo étnico de São Paulo, assim como nos jornais brasileiros, como, por exemplo, La Tribuna italiana, // Fanfulla, // Lavoro, // Ficcanaso, o Correio Paulistano, o Jornal do Brasil, o Jornal do Comércio, La Voce d'tália. Os fundadores foram incentivados por um design ambicioso, de modo a prefigurar, nos pôsteres publicitários, uma multiplicidade de itinerários que incluíam escolas de ensino fundamental, técnico e de ginástica, além de um curso noturno para adultos, juntamente com uma rica oferta de ensinamentos, como contabilidade, idiomas modernos, música, canto, ginástica e trabalhos femininos, como costura, corte, concerto, bordado, entre outros, para meninas (AI NOSTRI MONTI., s. d.).

A escola foi apresentada como um colégio para ambos os sexos, no qual a educação era ministrada "de acordo com as regras mais rigorosas da pedagogia científica moderna" (AI NOSTRI MONTI, 1895, p. 23), e pelos programas oferecidos na Itália e a legislação brasileira. A originalidade do colégio deveria ser equipada como um colégio interno destinado a receber não apenas os alunos convidados que pagavam 
uma taxa, mas, também, duas vagas externas gratuitas e internas, de ambos os sexos, cujos custos de manutenção foram sustentados pelo próprio internato. O nome "estudiosamente batizado" teve sua origem na necessidade de "manter vivo e sempre acordado nessas regiões distantes, o sentimento pátrio e a recordação de nossa Itália, berço das ciências, letras, artes, professora de direito no mundo, mansão das musas e das sereias, sorriso de Deus" (AI NOSTRI MONTI, 1895, p. 23, tradução nossa). O regulamento da instituição indicou o programa com as seguintes palavras:

\begin{abstract}
Neste instituto, será tomado o máximo cuidado para sempre manter vivo e sempre despertar o sentimento pátrio, a memória de nossa Itália e o culto nas páginas esplêndidas que ilustram a história gloriosa de nosso país em todas as épocas, sempre buscaremos a lei ética, pedagógica e higiênica para formar o coração da juventude, desenvolver sua inteligência e apoiar o desenvolvimento físico do organismo, para que a Pátria acolha cidadãos, homens honestos e bem vestidos e braços saudáveis e robustos, adequados para o trabalho e as armas (AI NOSTRI MONTI, 1895, p. 33, tradução nossa).
\end{abstract}

No entanto, o regulamento também expressou o sentimento de gratidão em relação ao país anfitrião, garantindo "grande cuidado à instrução e a educação brasileira" (AI NOSTRI MONTI, 1895, p. 24, tradução nossa), em conformidade com a legislação estadual atual das escolas, e "mantendo as portas do nosso internato abertas também para as crianças do país" (AI NOSTRI MONTI, 1895, p. 24, tradução nossa).

O colégio possuía estatuto e regulamento. Com o primeiro, aprovado em 13 de fevereiro de 1895, foram estabelecidos os três órgãos de governo do colégio-interno: a administração, a comissão e o conselho disciplinar. A comissão, presidida por Girolamo De Cunto ${ }^{2}$, foi convocada, acima de tudo, para gerenciar as assinaturas relacionadas à alocação de vagas gratuitas e tinha que garantir que as ofertas de "caridade pública" fossem gerenciadas com critérios sólidos, mas, entre as suas tarefas, havia também o de trabalhar para que o instituto "perca seu caráter de instituição privada governada arbitrariamente e sem controle, e se torne um instituto duradouro, não sujeito aos eventos caprichosos daqueles que o fundaram" (AI NOSTRA MONTI, 1895, p. 16). Em essência, o objetivo era obter do governo italiano o título de escola pública gratuita para todos (AI NOSTRI MONTI, 1895, p. 13-14). Depois que o colégio obtivesse o reconhecimento como instituto estatal, a comissão receberia o título de conselho disciplinar e seria chamada não apenas para supervisionar o progresso pedagógico e didático, mas também para exercer as mesmas funções atribuídas aos conselhos escolares provinciais da Itália. Da mesma forma, o presidente e o vice-presidente do conselho disciplinar teriam, respectivamente, a mesma autoridade na Itália que os supervisores reais e os inspetores das escolas. Em virtude desses objetivos, o conselho disciplinar foi presidido pelo cônsul real italiano e, como vice-presidente, pelo presidente (AI NOSTRI MONTI, 1895, p. 17).

Cada turma tinha que ter um professor regularmente autorizado a exercer a profissão e o ensino era previsto de acordo com os programas governamentais em vigor na Itália e não se estendia além das escolas primárias, a não ser excepcionalmente. No 
entanto, o idioma português era tão obrigatório quanto o italiano e, durante as horas de recreação, era permitido usá-lo. O ensino do conteúdo teórico da língua, no entanto, era esperado a partir do terceiro ano. Na $5^{\mathrm{a}}$ aula, então, estava prevista a possibilidade de ensinar francês. Quanto ao ensino religioso, "cada homem de família se entenderá com o diretor" (AI NOSTRI MONTI, 1895, p. 34, tradução nossa).

Os cursos se iniciavam em 2 de janeiro e terminavam em outubro; os meses seguintes, de novembro e dezembro, foram utilizados para repetições, passeios e visitas educacionais "pela cidade, em oficinas mecânicas e fábricas industriais" (AI NOSTRI MONTI, 1895, p. 35, tradução nossa). No que se refere aos exames finais de promoção, de dispensa e de licença elementar, o instituto fez referência ao regulamento único sobre instrução primária de 16 de fevereiro de 1888. Entre os aspectos originais previstos pelo regulamento, havia a proibição de distribuir prêmios por ocasião da celebração relativa à distribuição de certificados de promoção e licença porque é considerado "um meio educacional antipedagógico".

As fontes de subsistência do instituto foram representadas pelas mensalidades dos alunos e por contribuições voluntárias dos italianos que viviam em São Paulo. A matrícula na escola previa um custo elevado. A mensalidade, de fato, era de 5 mil réis; a referente aos exames de dispensa, de 10 mil réis e, finalmente, para obter uma superior, 15 mil réis.

Como já mencionado, o colégio incluiu um internato destinado a acomodar crianças com idades entre 6 e 12 anos. A permanência da estrutura era regulada por regras muito estritas, funcionais para a transmissão de modelos educacionais baseados em uma disciplina quase militar, confiada a tutores. No entanto, "punições manuais, meios educacionais draconianos, ruínas da barbárie bestial da Idade Média" (AI NOSTRI MONTI, 1895, p. 39, tradução nossa) eram absolutamente proibidos de acordo com os princípios do modelo de pedagogia científica moderna inspirada no positivismo.

A iniciativa de abrir o instituto destinado aos "numerosos e esforçados compatriotas" residentes em São Paulo foi muito apreciada pelo cônsul Compans de Brichanteau, que não apenas confirmou que a escola era frequentada e que o ensino transmitido era inspirado por "sentimentos puramente italianos" (TORRACA, 1897), como, depois de examinar a documentação de apresentação entregue pelos cônjuges, escreveu uma carta circular, na qual incentivava os fundadores a continuar com a "missão não fácil", que visava manter "vivo o sentimento de italianidade". Em particular, o cônsul enfatizou a ampla referência aos programas do governo italiano, e garantiu sua intervenção com as autoridades políticas italianas para fazer com que o instituto estivesse entre as escolas às quais pudesse alocar "méritos especiais" (AI NOSTRI MONTI, 1895, p. 31-32, tradução nossa).

Durante os três primeiros anos de atividade, o colégio desenvolveu os percursos relacionados às escolas elementares e sofreu um problema de mudança frequente de local: houve duas mudanças em prédios diferentes para compensar o custo dos aluguéis. O número de alunos matriculados foi de 78, muitos deles externos. No entanto, a primeira mudança de sede determinou a passagem para o internado de todos os alunos matriculados. Após a mudança de local, havia 89 alunos matriculados em 1897, 55 deles do sexo masculino e 24 do sexo feminino. Entre estes, os alunos do internato eram 30 meninos e 2 meninas (NESI, 1897, p. 2-3). 


\section{A PRODUÇÃO EDITORIAL}

Para assegurar a escolaridade dos filhos de emigrantes italianos, o compromisso do casal Nesi também foi direcionado para garantir materiais escolares adequados, como os livros didáticos. Nesse sentido, entre 1895 e 1897, eles se dedicaram a escrever silabários e a ler livros para as várias classes elementares. Como destacado em outras contribuições, a distribuição de livros didáticos no exterior também foi regulamentada pelo Ministero degli Affari Esteri (Ministério das Relações Exteriores) (BARAUSSE, 2019). No entanto, a circulação de livros escolares nem sempre refletiu as indicações fornecidas pela direção geral com base nas avaliações das comissões criadas e responsáveis por essa tarefa. Os relatórios dos cônsules de São Paulo confirmam a existência de uma certa desconexão entre o que é indicado e o que foi, de fato, enviado ${ }^{3}$. A produção dos cônjuges Nesi enquadra-se nessa produção não reconhecida pelas autoridades ministeriais, apesar do pedido ter sido apresentado pelos dois autores ${ }^{4}$. Uma das peculiaridades da produção dos cônjuges era a de ter utilizado a rede editorial paulista, e não a italiana.

Os livros didáticos constituem um capítulo muito significativo no estudo das culturas escolares, de acordo com Julia (1996) e Vinão Frago (1995), veiculadas por escolas italianas no Brasil e, em particular, em São Paulo. Duas edições das obras dos cônjuges foram encontradas e estão salvaguardadas no Arquivo histórico diplomático do Ministério das Relações Exteriores - ASMAE. No mesmo ano de 1895, os dois escritores produziram o silabário e as primeiras leituras no mesmo volume. Com a nova edição, publicada em 1896, as duas seções foram diferenciadas: associando-se à linha de tendência mais difundida na época na Itália, as primeiras leituras eram um produto associado, mas distinto do silabário, e seus objetivos não eram exclusivamente incentivar a aquisição de habilidades de leitura, mas também de aquisição de valores, normas e modelos de ensino e disciplina civil e social (BARAUSSE, 2014). O trabalho foi concluído com a publicação das leituras para a segunda e a terceira classe do ensino fundamental, mas o plano editorial também incluiu a publicação das leituras para a quarta e a quinta classe.

Os autores, ao enviarem os volumes à Comissão Central para a avaliação, definiram seu trabalho como "modesto", mas ao mesmo tempo "favorável" para:

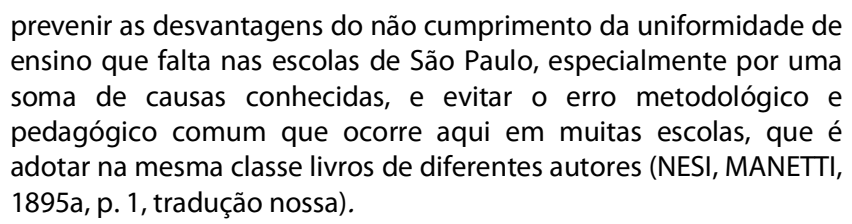
ensino que falta nas escolas de São Paulo, especialmente por uma soma de causas conhecidas, e evitar o erro metodológico e pedagógico comum que ocorre aqui em muitas escolas, que é adotar na mesma classe livros de diferentes autores (NESI, MANETTI, 1895a, p. 1, tradução nossa).

Para tanto, os autores partem de considerações didáticas e pedagógicas para justificar a redação dos textos. No entanto, as preocupações didáticas também estavam na origem da escolha dos cônjuges para produzir um texto mais adequado às necessidades locais brasileiras do que às italianas, conforme especificado na "Advertência" da abertura de cada texto: 
BARAUSSE, A.

\begin{abstract}
Impor às crianças que moram aqui o livro escrito para as crianças que vivem na Itália é como querer vestir um lombardo, no mês de janeiro, no Brasil, as mesmas roupas que naquele mês um italiano veste em Turim ou Belluno. Essa reflexão nos aconselhou a compilar os livros para as escolas italianas desta Federação. Confiantes em ter feito algo útil para nossos pequenos compatriotas, recomendamos nossas obras aos professores e aos pais da família (NESI; MANETTI, 1895a, p. 7, tradução nossa).
\end{abstract}

A publicação dos volumes foi amplamente divulgada pela imprensa étnica e, em geral, os comentários das publicações tiveram como objetivo destacar o papel original de precursor que os livros dos dois professores italianos pretendiam ter no contexto da produção editorial da época destinada às escolas italianas no exterior. Um dos colaboradores do // Ficcanaso, Leopoldo Del Rocchi, ao revisar os volumes dos cônjuges Nesi, destacou o trabalho pioneiro, pois foi a primeira experiência de publicação direta em contextos coloniais. Como tal, poderia ser um modelo de referência para futuros trabalhos escolares. As razões que o levaram a expressar um valor positivo em relação aos livros escolares dos Nesi foram "pioneiros da civilização futura" e "apóstolos de um futuro melhor" (DEL ROCCHI, 1895).

As observações do jornal foram apoiadas por uma forte ideia relacionada à função do livro como ferramenta fundamental para garantir o desenvolvimento do processo civilizatório que, atravessando as fazendas, entrando nas casas dos colonos, encontraria "crianças abandonadas ou mal orientadas, homens incultos ou maus" (DEL ROCCHI, 1895, s. p., tradução nossa), "teria diminuído as trevas da ignorância e do vício" (DEL ROCCHI, 1895, s. p., tradução nossa).

O silabário da nova edição apresenta a estrutura clássica dos primeiros livros destinados ao ensino contemporâneo da escrita e da leitura introduzidos na segunda metade do século XIX, dividido basicamente em duas partes. Na primeira, ele apresentou o tratamento de vogais e semiconsoantes, para depois passar à ilustração dos ditongos e hiatos; depois, introduziu consoantes e sílabas diretas e inversas. A maneira como as consoantes foram apresentadas foi caracterizada por grande variabilidade. Quase sempre, desde as primeiras páginas, o texto, na segunda edição, era acompanhado por uma lista de palavras e imagens demonstrativas que se referiam principalmente a animais. Nas páginas mais avançadas, destinadas a exercitar o aluno para incentivar o desenvolvimento lexical, também foram inseridas frases muito simples, juntamente com as palavras, de provérbios das máximas morais, como "Quem dorme não captura peixe" (NESI; MANETTI, 1896b, p. 24, tradução nossa), "Quem tem tempo ou filho não perde tempo" (NESI; MANETTI, 1896b, p. 26, tradução nossa), "Pierino ama a escola" (NESI; MANETTI, 1896b, p. 29, tradução nossa), "A estudante tola nunca aprende nada" (NESI; MANETTI, 1896b, p. 31, tradução nossa); ou tons patrióticos, como "Luciano ama e honra a bandeira italiana" (NESI; MANETTI, 1896b, p. 25, tradução nossa).

A primeira edição, que combinava silabário e leituras, introduziu, em uma segunda parte, palavras mais complexas para enriquecer a nomenclatura (NESl; MANETTI 1896b, p. 34-38, tradução nossa) e, em uma terceira parte, frases gradualmente mais articuladas que se referiam ao corpo humano, aos dias da semana, aos meses do ano, às quatro estações do ano, aos animais de estimação, à família, aos superiores, à escola, ao material escolar, à oração religiosa, ao lar, à obediência, à idade do homem, ao 
amor filial, ao tempo, à Umberto I de Savoia, à rainha da Itália; ou à histórias curtas de natureza moral, como "Dois verdadeiros amigos" (NESI; MANETTI 1896c, p. 39-64).

Os dois livros de leitura destinados a segunda e terceira classes, por outro lado, apresentaram uma distribuição diferente da estrutura e do conteúdo, desenvolvida sobretudo em relação às necessidades, muito percebidas pelas classes burguesas italianas, de favorecer os processos de nacionalização (SOLDANI; TURI, 1993). O segundo volume de leituras foi articulado por meio da coleta de pequenas passagens, histórias e poemas que transmitem modelos educacionais baseados na aquisição de valores funcionais para a regulação civil e social, tanto no país de origem quanto no país no qual os alunos imigrantes italianos eram considerados convidados (NESI; MANETTI, 1895C, tradução nossa). A diferenciação entre o segundo e o terceiro volume também foi marcada pelo diferente grau de complexidade e dificuldade.

O terceiro volume, por outro lado, continha maiores conteúdos atribuíveis a noções histórico-geográficas e científicas. Menores foram as referências à educação moral expressas através de diferentes formas. Por um lado, o livreto usava o gênero específico da carta escrita pela mãe, "Conselho da mãe", ou fechando algum conto histórico para relembrar o bom comportamento. Por outro lado, a educação moral foi introduzida de diferentes formas, incluindo o uso de perfis biográficos pertencentes à cultura clássica para recordar o valor moral de alguns comportamentos prezados pela cultura das classes burguesas italianas do século XIX, como o respeito pelo professor (Pitágoras), o amor filial (Tito Manlio), tenacidade e lealdade (Cinegiro) e aceitação da própria condição (Caio Fabrizio). Esses perfis foram, então, flanqueados por aqueles mais relacionados ao mundo do trabalho, como o pedreiro, o ferreiro, o pedreiro, o carpinteiro, o ferreiro, o tanoeiro, o oleiro: artesanato, artes e profissões (NESI; MANETTI, $1895 d$, p. 55, tradução nossa), funcional para fortalecer as qualidades morais do bom trabalhador, como paciência, amor diligente, constância, de acordo com os cânones da maioria dos manuais escolares da segunda metade do século XIX, vinculados ao ensino da língua (BACIGALUPI; FOSSATI, 1986).

Predominantes foram as referências ao tema do apego à pátria, expressas com fortes tons sentimentais, de acordo com a concepção "materna" da Itália usada nas leituras escolares e destacada por Chiosso (2013, p. 99), como na seguinte passagem:

\footnotetext{
Eu amo a Itália porque minha mãe é italiana, porque o sangue que corre em minhas veias é italiano, porque é italiana a terra onde estão sepultados os mortos que minha mãe chora e meu pai venera, porque os meus companheiros, meus irmãos, minha irmã, os livros que me educam são italianos. Bela Itália, grande e gloriosa por muitos séculos, unida e livre há poucos anos; mãe augusta de trezentas cidades e trinta milhões de filhos; Eu, garoto, venero e amo você com toda a minha alma e tenho orgulho de ter nascido de você e me chamar de seu filho. Eu amo os seus sagrados mares esplêndidos e suas sublimes montanhas; Amo seus monumentos solenes e suas memórias imortais. Eu te amo, minha pátria sagrada! E juro que serei um cidadão honesto e diligente, para tornar seu filho digno. Juro que te servirei com inteligência, com braço, com oração; e se um dia, por força dos acontecimentos, terei que dar
} 
BARAUSSE, A.

\begin{abstract}
meu sangue e minha vida por você, voarei para o seu ventre, para morrer com o seu santo nome na boca, mandando o último beijo para sua bandeira abençoada e o último olhar aos picos das minhas queridas montanhas! (NESI; MANETTI, 1895d, p. 7, tradução nossa).
\end{abstract}

As passagens no segundo e no terceiro volumes dedicados ao aprimoramento da identidade nacional são frequentes e incluem a homenagem aos soberanos, a memória relacionada à celebração dos feriados italianos, incluindo o estatuto, as moedas nacionais, as referências ao papel da capital Roma, a ilustração dos perfis funcionais para aprimorar funções nacionais no exterior, como os cônsules reais ou destinados à construção da memória, como os dos pais da pátria. Entre eles, os autores colocados ou as figuras que historicamente haviam desempenhado um papel significativo no marco do Risorgimento, o "meritório" entre os quais Carlo Alberto, entre os maiores arquitetos dos impulsos pela unificação, representava Massimo D'Azeglio, Cavour, Cairoli. Como estadistas de verdade; ou os de Mazzini, Gioberti, Pellico, Manzoni, identificados como escritores patrióticos, "nomes sagrados" do panteão nacional e Giuseppe Garibaldi que, no panorama dos protagonistas da "chama do heroísmo e do gênio da guerra", eram os mais completos:

Ele era um mestre, marinheiro, trabalhador, comerciante, soldado, general, ditador. Era grande, simples, bom. Ele odiava opressores, protegia todos os fracos; ele não tinha outra aspiração senão o bem, recusava honras, desprezava a morte, adorava a Itália. Quando jogou um bruto de guerra, legiões de valores reuniram-se a ele de todos os lados: os cavalheiros deixaram os prédios, os trabalhadores as oficinas, os jovens as escolas, para irem lutar ao sol de sua glória. Durante a guerra, ele usava uma camisa vermelha. Ele era forte, loiro, bonito. Nos campos de batalha, havia relâmpagos, nas afeições de uma criança, nas dores de um santo" (NESI; MANETTI, 1895d, p. 44, tradução nossa).

Foram também lembrados os eventos que colaboraram na construção do processo unitário ou que poderiam melhorar a memória coletiva, como a batalha de Lissa, a de Mântua, em novembro de 1866 ou, a fim de aumentar a honra de morrer pela pátria, a história de Dogali. No entanto, a apresentação dos conteúdos funcionais da educação civil também se traduziu na ilustração da divisão administrativa do estado, das regiões italianas e dos deveres do cidadão, expostos de acordo com o típico espírito mazziniano.

No entanto, além dos elementos que visavam construir a identidade nacional italiana, havia também aqueles funcionais para a integração no que era considerado o país anfitrião, o Brasil. Para esse fim, as leituras dedicavam-se em descrever os feriados nacionais do Brasil (NESI; MANETTI, 1896c, p. 29-30; NESI; MANETTI, 1896d, p.80-81), as moedas (NESI; MANETTI, 1896d, p. 41-42), conhecimento geográfico, como fronteiras, nomes de estados e capitais (NESI; MANETTI, 1896d, p. 18-20; NESI; MANETTI, 1896d, p. 33-34), bandeira (NESI; MANETTI, 1896d, p. 70) e notas sobre a história do Brasil (NESI; MANETTI, 1896d, p. 44-45) .

A adaptação do texto às condições do estado sul-americano refletiu-se, no entanto, também pelos conteúdos mais científicos tratados nos volumes e, em 
particular, pela representação da flora e da fauna. O ambiente natural brasileiro foi utilizado para introduzir e educar as crianças no conhecimento elementar de animais, plantas e minerais típicos do contexto migratório. Nesse sentido, seguindo o princípio da gradualidade, o terceiro volume sistematizou e classificou o conteúdo da educação científica de forma pré-científica, através da divisão entre o reino animal, o vegetal e o mineral (NESI; MANETTI, 1895d, p. 11). Os elementos da cultura científica, então, de acordo com outro tópico típico das leituras produzidas durante o segundo século XIX italiano (BACIGALUPI; FOSSATI, 1986), foram usados para apoiar a luta contra superstições e crenças na cabala e ressaltar os valores da honestidade, do trabalho e da economia de poupança; valores que, de acordo com Chiosso (2013), ao final do século, tornaram-se não apenas deveres prescritos, mas uma oportunidade para melhorar a própria existência.

ITALIAN ETHNIC SCHOOLING AND SCHOOL CULTURE IN SÃO PAULO: GAETANO NESI AND GEMMA MANETTI'S INITIATIVES FOR ITALIAN SCHOOL CHILD BETWEEN THE END OF NINETEENTH AND EARLY TWENTIETH CENTURY

ABSTRACT: The text uses unpublished sources to present the proposal for an investigation of the network of Italian elementary schools promoted in the State of São Paulo and the circulation of school knowledge by Italian childhood. The objective is not only to begin the reconstruction of a map of Italian schools in the context of São Paulo and São Paulo, but also to clarify their nature (associative, private, subsidized, religious, etc.), the characteristics (articulation and composition of mixed classes by age or sex, number of registered and effective students, registration fees and livelihoods), organisation and educational and pedagogical content (day and night school, articulation in degrees, mnemonic or intuitive teaching, curriculum contents including history and geography or catechesis), characteristics, training and condition of teachers. In this perspective, the text aims to deepen the role played by the couple Gaetano Nesi and Gemma Manetti Nesi promoters of the school «Ai Nostri Monti» and editorial initiative to educate the children of Italians and speed up the learning of writing and reading.

KEYWORDS: Italian Ethnic Schooling. Italian Migration in São Paulo. School Culture. Textbooks.

ESCOLARIZACIÓN ÉTNICA ITALIANA Y CULTURA ESCOLAR EN SÃO PAULO: LAS INICIATIVAS DE GAETANO NESI Y GEMMA MANETTI POR LA INFANCIA ESCOLAR ITALIANA ENTRE FINALES DE 1800 Y PRINCIPIOS DE 1900

RESUMEN: El texto recurre a fuentes inéditas para presentar la propuesta de una investigación de la red de las escuelas elementares italianas promovida en el Estado de São Paulo y de la circulación 
BARAUSSE, A.

de los saberes escolares por la infancia italiana. El objetivo no es solo iniciar la reconstrucción de un mapa de las escuelas italianas en el contexto paulista y paulistano, sino también aclarar su naturaleza (asociativa, privada, subsidiada, religiosa, ect.), las características (articulación y composición de las clases mixtas por edad o por sexo, número de inscritos y efectivos, tasas de inscripción y formas de subsistencia), la organización y los contenidos educativos y pedagógicos (escuela diurna y nocturna, articulación en grados, enseñanza mnemónica o enseñanza intuitiva, contenidos curriculares incluyendo historia y geografía o catequesis), las características, formación y condición de los profesores. En esta perspectiva, el texto pretende profundizar el papel ejercido por Gaetano Nesi y Gemma Manetti Nesi promotores de la institución escolar «Ai Nostri Monti» y de iniciativa editorial para educar a los hijos de los italianos y agilizar el aprendizaje de la escritura y de la lectura.

PALABRAS CLAVE: Escolarización Étnica Italiana. E/inmigración Italiana en São Paulo. Cultura Escolar. Libros Escolares.

\section{NOTAS}

1 - "Infelizmente, nossos emigrantes agrícolas chegam aqui analfabetos, vivem aqui, morrem ou retornam analfabetos. É claro que essa é a regra, a título de exceção, pois há algum emigrante que sabe alguma coisa, assim como eu entendo que lá nas fazendas, há algum agricultor ou funcionário administrativo que ensina leitura e escrita para pequenos grupos de crianças em idade escolar" (PIO DI SAVOIA, 1906a, p. 3).

2 - De acordo com Cenni (2003), ele era médico e, durante a propagação da febre amarela, dirigiu a Cruz Branca em Santos.

3 - Gherado Pio di Savoia, por exemplo, teria mencionado o livro Cuore, de Edmondo De Amicis ou La Patria nostra, de Angelo De Gubernatis; as leituras de Marcello Zaglia, tituladas // libro di Maria e Il libro di Lisa; o livro de Geografia por Giannitrapani, os Racconti della Patria de Soli, o Cálculo intuitivo de Ballocco. Mas não havia os silabários.

4 - Na ocasião da segunda edição dos livros, Gaetano Nesi também enviou uma carta ao rei para que ele pudesse apoiar o esforço econômico da escola (Lettera di Gaetano Nesi del 31 ottobre 1896. In: ASMAE, AS POS III, b. 341, sf. San Paolo PG fino al 1905); posteriormente, com uma nova carta, ele insistiu novamente com o Ministro de Relações Exteriores que a produção editorial pudesse obter reconhecimento (Lettera di Gaetano Nesi e Gemma Manetti del 4 gennaio 1897 al ministro degli Affari Esteri. In: ASMAE, AS POS III, b. 341, sf. San Paolo PG fino al 1905).

\section{REFERÊNCIAS}

AI NOSTRI MONTI. Ateneo Convitto Italiano d'ambo i sessi diretto dai Signori Prof. G. Nesi e Gemma Manetti Nesi Benemeriti della Istruzione Popolare in Italia. Statuto e Regolamento. S. Paolo (Brasile): Typographia Paulista, 1895.

ASCENZI, A.; BARAUSSE, A.; LUCHESE, T. Â.; SANI, R. Migrations and History of education in a transnational view between Italy and Brazil in 19th and 20th centuries. History of Education \& Children's Literature, Macerata, v. XIV, n. 2, XIV, p. 227-262, 2019. 
BACIGALUPI, M.; FOSSATI, P. Da plebe a popolo. L'educazione popolare nei libri di scuola dall'unità alla repubblica. Firenze: La Nuova Italia, 1986.

BARAUSSE, A. Una impronta di italianitá: os livros didáticos para as escolas étnicas italianas no Brasil entre o liberalismo e o fascismo. Cadernos de História da Educação (ONLINE), Uberlândia, v. 18, n. 2, 2019, p. 329-350.

BARAUSSE, A. Learning to read and write in Italy in the second half of the nineteenth century. Primers and reading exercise booklets. Publications, ministerial control and teaching (1861-1898). History of Education \& Children's Literature (Online), Macerata, v. 9, n. 1, 2014, p. 109-149.

BARAUSSE, A. Le scuole italiane nel Rio Grande do Sul attraverso le carte consolari tra la fine dell'Impero e l'inizio della Repubblica (1875-1893). In: DE RUGGIERO, A.; HEREDIA, V. B. M.; BARAUSSE, A. História e narrativas transculturais entre a Europa Mediterrânea e a América Latina. 1 ed. Porto Alegre: EDIPUCRS, 2017, v. 1, p. 195-248.

BARAUSSE, A.; GHIZZONI, C.; MEDA, J. «ll campanile scolastico». Ripensando la dimensione locale nella ricerca storico-educativa. Rivista di storia dell'educazione, Firenze, v. 5, n. 1, 2018, p. 7-14.

CENNI, F. Italianos no Brasil: "Andiano in Merica". 3ª ed. São Paulo: EDUSP, 2003.

CHICCO, E. Relazione Scuole italiane in San Paolo del r. Console E. Chicco del 3 maggio 1897. In: ASMAE, AS, POS III, b,. 341, f. Scuole italiane sussidiate nello Stato di San Paolo G 184, 1897. n. p.

CHIOSSO, G. Libri di scuola e mercato editoriale. Dal primo Ottocento alla Riforma Gentile. Milano: Franco Angeli. 2013.

CONZEN, K. N. et al. (ed.). The Invention of Ethnicity in the United Sates. Journal of America Ethnic History, Chicago, v. 1, s. n., 1992, p. 3-41.

DEL ROCCHI, L. Ai Nostri Monti. II Ficcanaso, São Paulo, n- 3, 3 março 1895. In: ASMAE, AS, POSIII, b. 341, f. S. Paolo PG fino al 1905. n. p.

GIOIA. Elenco delle scuole italiane nella città di San Paolo e nello Stato al 31 marzo 1900. In: ASMAE, AS, POS III, b. 341, f. Scuole sussidiate nello stato di San Paolo G 184, 1900. n. p.

HALL, M. Imigrantes na cidade de São Paulo. In: PORTA, P. (org). História da cidade de São Paulo: a cidade na primeira metade do século XX. São Paulo: Paz e Terra, v. 3, s. n., 2004, p. 121-151. 
BARAUSSE, A.

HOBSBAWN, E.; RANGER, T. Introdução: a invenção das tradições. In: HOBSBAWN, E.; RANGER, T. A invenção das tradições. 3. ed. São Paulo: Paz e Terra, 2002. p. 9-23.

JULIA, D. A cultura escolar como objeto histórico. Revista Brasileira de História da Educação, Campinas, v. 1, n. 1, jan./jul. 2001.p. 9-43.

LUCHESE, T. Â. O processo escolar entre imigrantes no Rio Grande do Sul. Caxias do Sul: EDUCS, 2015.

MAGALHAES, J. A instituição educativa na modernização do local. Perspectiva históricopedagógica. Rivista di storia dell'educazione, Firenze, v. 5, n. 1, 2018, p. 41-55.

MONACO, Scuole italiane esistenti nello Stato di San Paolo. Annesso al rapporto del 15 settembre 1902. In:ASMAE, AS, POS III, b. 341, sf. fino al 1900. 1902. n. p.

NESI, G.; MANETTI, G. Lettera di Gaetano Nesi e Gemma Manetti del 27 agosto 1895. In: ASMAE, AS POS III, b. 341, sf. San Paolo PG fino al 1905, 1895a. n. p.

NESI, G. Lettera di Gaetano Nesi del 31 ottobre 1896. In:ASMAE, AS POS III, b. 341, sf. San Paolo PG fino al 1905, 1896. n. p.

NESI, G.; MANETTI, G. Lettera di Gaetano Nesi e Gemma Manetti del 4 gennaio 1897 al ministro degli Affari Esteri. In: ASMAE, AS POS III, b. 341, sf. San Paolo PG fino al 1905, 1897. n. p.

NESI, G. Relazione di Gaetano Nesi al Console generale d'Italia Enrico Chicco del 27 maggio 1897. In:ASMAE, AS POS III, b. 341, sf. San Paolo PG fino al 1905, 1897. n. p.

NESI, G., MANETTI NESI, G. I piccoli italiani nel Brasile. Sillabario e prime letture. Ad uso delle Scuole Italiane Maschili e Femminili del Brasile. S. Paulo: Tyographia Paulista, 1895b.

NESI G., MANETTI NESI, G. 2 ed., I piccoli italiani nel Brasile. Sillabario ad uso delle Scuole Italiane Maschili e Femminili del Brasile. S. Paulo: Editora Melillo \& C, 1896a.

NESI, G., MANETTI NESI, G. I piccoli italiani nel Brasile. Prime letture. S. Paulo: Livraria Teixeira Editora Melillo \& C, 1896b.

NESI, G., MANETTI NESI, G. I piccoli italiani nel Brasile. Secondo libro di lettura. Ad uso delle Scuole Italiane Maschili e Femminili del Brasile. S. Paulo: J. B. Endrizzi \& Comp, 1896c.

NESI, G., MANETTI NESI, G. I piccoli italiani nel Brasile. Terzo libro di lettura. Ad uso delle Scuole Italiane Maschili e Femminili del Brasile. S. Paulo: J. B. Endrizzi \& Comp, 1896d.

Inter-Ação, Goiânia, v.46, n.2, p. 422-440, maio/ago. 2021. Disponível em: <http://dx.doi.org/10.5216/ia.v46i2.67954>. 
NORME pel funzionamento delle scuole italiane nello Stato di San Paolo. Sem Editor. In: ASMAE, b. 341, f. [Scuole italiane sussidiate nello Stato di San Paolo] fino al 1900 G. 184, 1904. n. p.

PANIZZOLO, C. A escola étnica na cidade de São Paulo e os primeiros tons de uma identidade italiana (1887- 1912), História da educação (Online), Porto Alegre, v. 24, s. n., 2020. DOI: http://dx.doi.org/10.1590/2236-3459/91636.

PIO DI SAVOIA. Scuole italiane in San Paolo nel 1905. Rapporto del r. console generale Gherardo Pio di Savoia del 6 gennaio 1906, p. 2,1906a.

PIO DI SAVOIA. Per le scuole italiane. Anno Scolastico 1906. Relazione del Console Gherardo Pio di Savoia al ministero degli Affari Esteri del 29 luglio 1906, 1906b.

POLLAK, M. Memória e identidade social. Revista Estudos Históricos, São Paulo, v. 5, n. 10, p. 200-215, 1992. Disponível em:

$<$ http://bibliotecadigital.fgv.br/ojs/index.php/reh/article/view/1941/1080> . Acesso em: 4 fev. 2020.

POLLAK, M. Memória, esquecimento silêncio. Revista Estudos Históricos, São Paulo, v. 2, n. 3, p. 3-15, 1989. Disponível em: http://bibliotecadigital.fgv.br. Acesso em: 5 fev. 2020.

RIVA. Telespresso di Riva del 24 marzo 1890, Petropoli. In: ASMAE, b. 341, sf. Scuole italiane sussidiate nello Stato di San Paolo G 184, 1890. n. p.

ROZWADOWSKI, A.. Relatório do real cônsul de São Paulo de março 1900. In:ASMAE , AS, POS III, b.. 341, f. Scuole italiane sussidiate nello Stato di San Paolo G 184, 1890a. n. p.

ROZWADOWSKI, A. Relazione del console Conte Roznadowski Antonio L. 8 dicembre 1890. In: ASMAE, AS, POS III, b,. 341, f. Scuole italiane sussidiate nello Stato di San Paolo G 184, 1890b. n. p.

SOLDANI, S.; TURI, G. (Ed.). Fare gli italiani. Scuola e cultura nell'Italia contemporanea, vol. 1. La nascita dello Stato nazionale. Bologna: II Mulino, 1993.

STATUTO della Associazione fra gl'Insegnanti italiani di S. Paolo. S. Paolo: Tipografia Italiana N. Fortunati. In: ASMAE, b. 341, f. [Scuole italiane sussidiate nello Stato di San Paolo] fino al 1900 G. 184, 1902. n. p.

TORRACA, F. Nota di F. Torraca pel Ministro della Pubblica Istruzione del 7 giugno 1897. In:ASMAE, AS POS III, b. 341, sf. San Paolo PG fino al 1905, 1897. n. p. 
BARAUSSE, A.

TRENTO, A. De outro lado do Atlântico. Um século de Imigração Italiana no Brasil: São Paulo: Nobel, 1989.

TRENTO, A. In Brasile. In: Bevilacqua, P.; De Clementi, A.; Franzina, E. Storia dell'emigrazione italiana:I arrivi. Roma: Donzelli Editore, 2009, p. 3-23.

TRUZZI, O. Italianidade no interior paulista: percursos e descaminhos de uma identidade étnica (1880-1950). São Paulo: UNESP, 2016.

VINÃO FRAGO, A. Historia de la educacione historia cultural: possibilidades, problemas, cuestiones. Revista Brasileira de Educação, São Paulo, set/dez ANPEd, v. 1, 1995, p. 6382.

Alberto Barausse: Possui Doutorado em Educação - Universitá Cattolica del Sacro Cuore (1998). Tem experiência na área de Educação, com ênfase em História da Educação. Pesquisador na Universitá' degli Studi del Molise de 2001 até 2004. Professor Titular em História da Educação na Universitá degli Studi del Molise desde 2012 onde lidera o Centro de Documentação e Pesquisa sobre a História das Instituições escolares, o livro didático e a literatura infantil (CeSIS) e o Museu da Escola e da Educação Popular. Foi, também, professor e pesquisador visitante no programa de Pósgraduação em Educação da PUCRS e bolsista Pós-doc no programa de Pós-graduação em Educação da UFRGS.

Orcid: http://orcid.org/0000-0002-8326-046X

E-mail: barausse@unimol.it

Este periódico utiliza a licença Creative Commons Attribution 3.0, para periódicos de acesso aberto (Open Archives Initiative - OAI). 